\title{
Reading with Strategies: A Study of Young EFL Learners' Use of Online Reading Strategies
}

\author{
Chia-Hui Cindy Shen \\ Department of English, National Taiwan Normal University, Taipei 11174, Taiwan
}

\begin{abstract}
To assist young learners to cultivate efficient learning strategies in the early ages, students in the current study were guided to read three authentic online storybooks and then write their own digital stories with tablet PCs. The study aims to investigate Taiwanese elementary school students' use of online reading strategies, and their relationship with students' performance on reading proficiency tests. The target population consisted of upper-grade learners $(n=83)$. The instruments were a M-SORS (modified survey of reading strategy) questionnaire and a reading proficiency test. Major findings were as follows: (1) Students used online reading strategies at medium level; (2) problem solving strategies were proven to significantly correlate with students' performance on reading comprehension test; and (3) there was a significant difference between higher and lower reading proficiency learners' use of online reading strategies. Pedagogical implications of the findings and suggestion for future research are discussed.
\end{abstract}

Key words: Online reading strategies, reading proficiency, young EFL (English as a foreign language) learners.

\section{Introduction}

Currently, the emergence of mobile technologies is bringing new possibilities to language learning and literacy development. Elementary school teachers have started to contemplate the potential of using these emergent technologies to provide authentic language experiences. School teachers are encouraged to incorporate technology in their classrooms.

Digital story reading can enhance subject content learning, critical thinking skills, and literacy development. Digital story reading and writing also provides opportunities for students to monitor their learning process, thus fostering confidence and the sense of task accomplishment [1]. Each digital reading and writing challenges students to meticulously choose and compose their own storylines with the support of multimedia resources and thereby develop technical skills as well.

Corresponding author: Chia-Hui Cindy Shen, Ph.D. student, research fields: SLA, reading strategies, and computer-assisted language learning. E-mail: cindy422@tp.edu.tw.
Regarding the importance of the technology and its impact on language learning, the current study presents an empirical study conducted in an elementary school in Taiwan. The paper is organized as follows: Section 2 discusses second language reading strategies and online second language reading; Section 3 introduces the research questions; Section 4 is the methods; Section 5 demonstrates results; Section 6 is discussions and conclusions. Pedagogical implications and future work are further presented.

\section{Literature Review}

In this section, two major parts are presented. The first section elucidates the theoretical background of second language reading strategies. The second section discusses research on digital story reading in L2 contexts.

\subsection{Second Language Reading Strategies}

There are two dimensions of the studies on L2 reading in a second language. First, the interactive model for teaching and reading is the dynamic 
relationship between bottom-up and top-down processes, between decoding and interpretation, and between text and reader [2, 3].

The second dimension of L2 reading is that readers' language proficiency levels correlate to their choices in strategy use [4, 5]. High proficiency readers have a tendency to utilize global strategies. They also use more strategies that assist textual comprehension and apply more self-monitoring strategies when reading different difficulty levels [6, 7]. On the contrary, low achievers frequently use local strategies that are not specifically useful for comprehending the text as a whole $[7,8]$.

\subsection{Online Second Language Reading}

Few studies have been investigated online reading strategies. Online second language reading relies on multimedia features, such as automatic oral reading, digital highlighting, animations, sound effects, all of which are impossible with printed books. Research has shown that presenting students with visual representations of animated words and illustrations can help them overcome comprehension-processing difficulties [9]. Tablet PCs can be used to do e-books reading, with the potential for multimodal texts and multidimensional representations of background information.

The literature on online reading strategies investigates three dimensions. First, compared to paper-based storybooks, digital story reading is an innovative idea to motivate students to read independently [10]. Readers use different strategies when reading paper and online reading materials [11].

Second, recent studies have focused on labeling EFL/ESL (English as a foreign language/English as a second language) learners' online reading strategies [12]. Results indicated that reading strategies used by learners in print are transferable to online reading whether in ESL or in L1. For example, in Ref. [13], the result indicated that expert readers tend to skillfully transfer their print text reading strategies to the computer reading environments. The pedagogical implications are that it is suggested to integrate both text-related and web-related reading strategies in reading online texts. Moreover, the effective use of reading strategies has been recognized as an important way to increase reading comprehension.

Third, studies have demonstrated that there is a positive effect of computer-assisted strategy training on reading. For example, Coiro and Dobler [14] explored online reading comprehension strategies among elementary school sixth-grade skilled readers in a web-based reading program. The study found that students' reading comprehension is enhanced and the frequency of their strategy use, including prior knowledge sources, inferential reasoning strategies, and self-regulated reading processes also increased.

\section{The Present Study}

The following three research questions were addressed. First, what are the online reading strategies used by the young EFL learners in Taiwan? Second, what is the relationship between young EFL learners' online reading strategy use and their reading proficiency? Third, is there any difference between online reading strategies used by high and low proficiency learners?

\section{Method}

\subsection{Participants}

Five classes of upper-grade Chinese-speaking children $(n=83)$ at an elementary school in Taiwan were recruited to participate in the study. Students in this study were used to reading paper-based storybooks. Each student was equipped with individual tablet PC, which was used as a media for digital story reading and writing. To compare different proficiency students' online reading strategy use, students who scored at $\mathrm{H}$ (top 33\%) and L (bottom $33 \%)$ in the reading proficiency test were selected.

\subsection{Design and Materials}

There are three main criteria for selecting three 
appropriate storybooks for the participants in this study. First, the storybook should be a fiction with sufficient story elements, including plots, characters, setting, problems and solutions; therefore, students can easily collaborate and discuss with each other. Second, each animated storybook will have three levels, with each sharing similar content and vocabulary. Third, the book whether it is at the beginning, intermediate, or advanced level is about 120 to 530 words in length, which make it possible not only for the students in different levels to complete their own digital story reading and writing, but also for the teacher to conduct the post-reading discussion within the 40 minutes time frame of a class period. The word range for each level is $100-200$ for the beginning level; 200-350 for the intermediate level; and 300-550 for the advanced level.

\subsection{Treatment Procedure}

Students needed to read three online storybooks across 12 weeks. After that, they filled in online reading strategy use M-SORS questionnaire in L1, and then a reading proficiency test was administered. Higher and lower achievers' responses toward the questionnaire and performances in reading proficiency test were singled out for further analysis.

\subsection{Data Analysis}

Descriptive statistics was adopted to identify students' online reading strategies. The relationship between these students' use of online reading strategy and their reading proficiency tests were analyzed via Pearson product-moment correlations. Independent-sample $t$-tests were applied to examine whether there was any significant difference between higher and lower reading proficiency learners in their use of online reading strategies.

\section{Results}

Generally speaking, Taiwanese elementary school students used online reading strategies at medium level (Table 1).
Table 2 presents the result of the relationship between the three categories of metacognitive reading strategies and students' performance on the reading proficiency test. A Pearson correlation was conducted.

According to Table 2, problem solving strategies correlated significantly reading comprehension questions $(r=.203, p<.01)$. Neither global reading strategies nor support strategies correlated with any of the subtests.

As the result from Table 3, high proficiency learners not only scored significantly higher than low proficiency learners ( $t=28.87, p<.05$ ), but also performed more consistent than that of its counterparts.

Results displayed in Table 3 indicated that the proficiency levels of the two groups do differ from each other in the scores on reading proficiency test.

Table 4 further presents the overall strategy use between high and low reading proficiency students. For the high proficiency group learners $(n=27)$, their mean score was 3.56. Based on Oxford's key to understanding SILL averages, these students usually used online reading strategies. Low proficiency group, on the contrary, sometimes used online reading strategies $(M=3.21)$. The result of the $t$-test showed that such difference was significant $(\mathrm{t}=1.63, p<.05)$.

Table 1 The frequency of use of three categories of online reading strategies.

\begin{tabular}{lcccl}
\hline & $N$ & Mean & $S D$ & Frequency level \\
\hline $\begin{array}{l}\text { Overall } \\
\text { strategies }\end{array}$ & 83 & 3.43 & .45 & $\begin{array}{l}\text { Medium use (Range }= \\
\text { 2.5-3.4) }\end{array}$ \\
\hline
\end{tabular}

Table 2 Correlation between metacognitive reading strategies and reading proficiency test.

\begin{tabular}{ll}
\hline Metacognitive reading strategies & Reading proficiency tests \\
\hline Global reading strategies & 0.087 \\
Problem solving strategies & $0.203^{* *}$ \\
Support strategies & 0.116 \\
\hline
\end{tabular}

**: Correlation is significant at the 0.01 level (two-tailed).

Table 3 Scores on reading proficiency test between high and low proficiency learners.

\begin{tabular}{llllllll}
\hline & \multicolumn{3}{c}{$\mathrm{H}(n=27)$} & & \multicolumn{2}{c}{$\mathrm{L}(n=27)$} & \\
\cline { 2 - 3 } & Mean & $S D$ & & Mean & $S D$ & $t$ & $P$ \\
\hline Scores & 86.78 & 2.31 & 47.55 & 1.65 & $28.87 *$ & .00 \\
\hline${ }^{*} p<.05$. & & & & & & \\
\hline
\end{tabular}


Table 4 Overall strategy use between high and low reading proficiency students.

\begin{tabular}{lllllllll}
\hline & \multicolumn{3}{c}{$\mathrm{H}(n=27)$} & & \multicolumn{2}{c}{$\mathrm{L}(n=27)$} & & \\
\cline { 2 - 3 } & Mean & $S D$ & & Mean & $S D$ & $t$ & $P$ \\
\hline $\begin{array}{l}\text { Overall } \\
\text { strategy use }\end{array}$ & 3.56 & .34 & 3.21 & .55 & $1.63 *$ & .047 \\
\hline$* p<.05$ & & & & & & &
\end{tabular}

Table 5 Strategy category use between high and low reading proficiency group.

\begin{tabular}{lllllll}
\hline & Proficiency & $N$ & Mean & $S D$ & $t$ & $P$ \\
\hline \multirow{2}{*}{ GLOB } & H & 27 & 3.54 & .32 & \multirow{2}{*}{.54} & \multirow{2}{*}{.76} \\
& L & 27 & 3.21 & .72 & & \\
\hline \multirow{2}{*}{ PROB } & H & 27 & 3.98 & .50 & \multirow{2}{*}{$2.31^{*}$} & .05 \\
& L & 27 & 3.44 & .64 & & \\
\hline \multirow{2}{*}{ SUP } & H & 27 & 3.76 & .58 & \multirow{2}{*}{1.66} & \multirow{2}{*}{.21} \\
& L & 27 & 3.18 & .61 & & \\
${ }^{*} p<.05$ & & & & & &
\end{tabular}

In other words, students of high proficiency group used strategies more often than their low proficiency counterparts did.

The results of $t$-test were presented in Table 5 . Among the three categories of online reading strategies, high and low proficiency learners showed no difference in terms of global reading strategies $(t$ $=.54, p>.05)$ and support strategies $(t=1.66, p>.05)$. It was only in the problem solving category that the two proficiency groups showed a significant difference $(t=2.31, p<.05)$.

The results implied that students of both proficiency groups frequently used problem solving strategies ( $M$ $=3.98$ ) for high proficiency group and 3.44 for low proficiency counterpart, which fall into Oxford's classification of high use. In addition, problem solving strategies could differentiate students in the two reading proficiency groups.

In brief, among the three groups of online reading strategies, elementary school students tended to rely on problem solving strategies the most, followed by support strategies, and global reading strategies. Problem solving strategies were proven to significantly correlate with students' performance on reading comprehension test. Reading aloud was the least used online reading strategy by all participants. However, it was found to correlate significantly with learners' overall reading proficiency. In addition, it was a crucial strategy that distinguished high proficiency learners from low ones. Furthermore, there was a significant difference between high and low reading proficiency learners' use of online reading strategies, especially in the use of problem solving strategies. Low achievers' frequent use of translation method was found to negatively correlate to their reading performance.

\section{Discussion and Conclusion}

Among the three types of online reading strategies, young EFL learners tended to rely on PROB strategies the most, followed by SUP strategies, and GLOB reading strategies $[7,12,15]$. PROB strategies were proven to significantly correlate with students' performance on reading proficiency test. Moreover, there was a significant difference between higher and lower reading proficiency learners' use of online reading strategies, particularly in the use of PROB strategies [10].

\subsection{Pedagogical Implications}

The present study has demonstrated that the use of online reading strategies did play a critical role in learners' reading proficiencies. Within the 30 individual online reading strategies, reading aloud was the least used one, but it significantly separated high from low reading proficiency learners. Over dependence on translation resulted in lower reading proficiency levels. Followings are pedagogical implications that echo the above mentioned issues.

\subsubsection{The Use of Reading Aloud}

Based on the result of the present study, reading aloud was crucial in differentiating high achievers from low ones. When readers encountered comprehension breakdown, or read challenging articles, reading aloud was a strategy to enhance comprehending of a written text. The double enhancement of learning has also been proven to significantly correlate with learners' overall reading 
proficiency. Moreover, reading aloud allows readers to develop reading fluency while trying to understand the phrasing of a language and the sentence structures [16].

\subsubsection{Direct Teaching of Online Reading Strategies}

In the current study, the importance of online reading strategies has been reaffirmed. In addition, problem solving strategy group has also been found to be not only the most favored type of online reading strategies by elementary school students, they also play a crucial role in influencing learners' overall reading proficiency levels and performance on reading comprehension tests. To help learners improve their reading abilities, language teachers are recommended to give direct combined-strategy instruction of online reading to the young EFL learners [17-19].

\subsubsection{Limitations of the Present Study}

However, this study had several limitations. The first limitation concerns the number of participants. There were only 83 students participated in the study. Though significant results have been obtained through the responses of these EFL learners, it would definitely be more convincing if more elementary school students from different schools, or even various parts of Taiwan were to participate in the study.

Another limitation of the present study is that students' actual engagement in the strategies cannot be reported simply from a self-report questionnaire [14]. In other words, the participants chose what they believe rather than what they did. Moreover, the reasons behind the use of strategies cannot be further revealed simply through the results of questionnaires. Therefore, qualitative data from observations toward students' actual use of strategies and interviews of learners' decisions are needed.

\section{References}

[1] Banaszewski, T. 2002. "Digital Storytelling Finds Its Place in the Classroom.” Multimedia Schools 9: 1-32.

[2] Goodman, Y. M. 1986. What's Whole in Whole Language. Portsmouth, NH: Heinemann.
[3] Rumelhart, D. E. 2004. "Toward an Interactive Model of Reading.” In Theoretical Models and Processes of Reading, edited by Ruddell, R. B., Ruddell, M. R., and Singer, H. 5th ed.. International Reading Association, 1127-48.

[4] Hong-Nam, K., and Leavell, A. 2006. "Language Learning Strategy Use of ESL Students in an Intensive English Learning Context.” System 34: 399-415.

[5] Green, J. M., and Oxford, R. 1995. "A Closer Look at Learning Strategies, L2 Proficiency, and Gender." TESOL Quarterly 29: 261-97.

[6] Kletzien, S. B. 1991. "Strategy Use by Good and Poor Comprehenders Reading Expository Text at Different Levels.” Reading Research Quarterly 24: 67-85.

[7] Zhang, L. J., and Wu, A. 2009. "Chinese Senior High School EFL Students' Metacognitive Awareness and Reading-strategy Use.” Reading in a Foreign Language 21: 37-59.

[8] Gan, Z., Humphreys, G., and Hamp-Lyons, L. 2004. "Understanding Successful and Unsuccessful EFL Students in Chinese Universities.” The Modern Language Journal 88: 229-44.

[9] Liu, J. 2004. "Effects of Comic Strips on L2 Learners Reading Comprehension.” TESOL Quarterly 38: 225-43.

[10] Sadik, A. 2008. "Digital Storytelling: A Meaningful Technology-integrated Approach for Engaged Student Learning." Educational Technology Research and Development 56: 487-506.

[11] Foltz, P. W. 1993. "Readers' Comprehension and Strategies in Linear Text and Hypertext.” Unpublished doctoral dissertation, University of Colorado Boulder.

[12] Anderson, N. J. 2003. "Scrolling, Clicking, and Reading English: Online Reading Strategies in a Second/Foreign Language.” The Reading Matrix 3: 1-33.

[13] Block, E. 1992. "See How They Read: Comprehension Monitoring of L1 and L2 Readers.” TESOL Quarterly 26 (2): 319-43.

[14] Coiro, J., and Dobler, E. 2007. "Exploring the Comprehension Strategies Used by Sixth-grade Skilled Readers as They Search for and Locate Information on the Internet.” Reading Research Quarterly 42: 214-57.

[15] Hung, H. P. 2005. "An Investigation of Factors that Influence EFL College Students’ Reading Strategy Use.” Unpublished master thesis, Changhua: National Changhua Normal University.

[16] Fountas, I. C., and Pinnell, G. S. 1996. Guided Reading: Good First Teaching for All Children. Portsmouth, NH: Heinemann.

[17] Baker, L. 2001. "Metacognition in Comprehension Instruction.” In Comprehension Instruction: Research Based Best Practices, edited by Block, C., and Pressley, M. New York: Guilford, 274-89. 
[18] Mokhtari, K., and Sheorey, R. 2002. "Measuring ESL Students' Awareness of Reading Strategies.” Journal of Developmental Education 25: 2-10.

[19] Duke, N. K., and Pearson, D. 2002. "Effective Practices for Developing Reading Comprehension.” In What Research Has to Say about Reading Instruction, edited by Farstrup, A. E., and Samuels, S. J. Newark, DE: International Reading Association, 205-42. 